\title{
Fetal growth, glucose tolerance and plasma insulin concentration in rats given a marginal-zinc diet in the latter stages of pregnancy
}

\author{
By SUSAN SOUTHON AND SUSAN J. FAIR WEATHER-TAIT \\ AFRC Institute of Food Research, Colney Lane, Norwich NR4 7UA \\ AND CHRISTINE M. WILLIAMS \\ Department of Biochemistry, University of Surrey, Guildford, Surrey GU2 $5 X H$
}

(Received 6 July 1987 - Accepted 6 October 1987)

1. Wistar rats were fed on a control semi-synthetic diet throughout pregnancy, or a control diet in the first 2
weeks and a marginal-zinc diet in the 3 rd week of pregnancy. On day 20 , after an overnight fast, half the animals
in each group were given glucose by gavage and the $0-30$ min rise in blood glucose measured in tail blood. After
$60 \mathrm{~min}$ blood was taken by cardiac puncture for glucose and insulin assay. Maternal pancreases were removed and
the $\mathrm{Zn}$ contents measured. Fetuses from each litter were combined for wet/dry weights, protein and DNA the $\mathrm{Zn}$ contents
determinations.

2. Plasma insulin concentration was higher, and glucose concentration and pancreatic $\mathrm{Zn}$ content lower, in pregnant $v$. non-pregnant animals of similar age, fed on the same diet. Pancreatic $\mathrm{Zn}$ content was lowest in the marginal-Zn group of pregnant rats. Fetuses from mothers fed on the marginal-Zn diet during the last week of pregnancy were slightly heavier than controls and had a significantly higher protein:DNA ratio. The $0-30$ min rise in blood glucose was significantly greater in the marginal-Zn animals.

3. In a second experiment, pregnant rats were given similar diets to those used in the first study, but the marginal- $\mathrm{Zn}$ diet was given for a shorter period (days 15-19 of pregnancy). On day 19 the rats were meal-fed and on day 20 , after an overnight fast, an oral glucose dose was administered. Tail-blood was taken at timed intervals up to $60 \mathrm{~min}$ post-dosing for glucose assay. Both maternal and fetal blood glucose and insulin concentration was measured 70 min post-dosing.

4. Values for maternal and fetal blood glucose and plasma insulin, measured $70 \mathrm{~min}$ after the administration of a glucose dose, were similar in the two groups, but the initial rise in blood glucose concentration was again significantly higher in pregnant rats given the marginal- $\mathrm{Zn}$ diet towards term.

5. It is suggested that the change in growth and composition, observed in fetuses from rats given a marginal$\mathrm{Zn}$ diet in later pregnancy, is associated with altered maternal carbohydrate metabolism.

Rats given a marginal-zinc diet towards the end of pregnancy produce pups which are large for their gestational age. However, rats given a marginal-Zn diet from the start of pregnancy are no different from control-fed animals, and the earlier in pregnancy the marginal-Zn diet is introduced the less is the effect on fetal growth (Fairweather-Tait et al. $1984,1985)$. This indicates an adaptive response to longer periods of marginal-Zn intake. The reasons for the observed increase in fetal growth are unclear, but the fact that glucose is the major metabolic fuel for the developing fetus (Schwartz, 1968), together with evidence that inadequate dietary $\mathrm{Zn}$ results in abnormal carbohydrate metabolism in rats (Reeves \& O'Dell, 1983) and man (Baer et al. 1985), suggest that the increased size of pups may be linked to changes in glucose utilization.

This possibility was investigated by studying the effect of marginal- $\mathrm{Zn}$ intake during the latter stages of pregnancy in the rat on growth, blood glucose and insulin levels in the fetus, and maternal glucose tolerance and circulating insulin concentration.

\section{MATERIALS AND METHODS \\ Expt 1}

Adult virgin female Wistar rats $(250 \mathrm{~g})$, fed $a d$ lib. for 1 week on a control semi-synthetic diet, as described previously (Fairweather-Tait et al. 1984), were mated with Wistar rats overnight. The following morning (day 0 of pregnancy) they were randomly divided into 
two groups. The first group was given a control diet (60 mg Zn/ $\mathrm{kg}$ diet) throughout pregnancy. The second group received the control diet for the first 2 weeks of pregnancy followed by a marginal- $\mathrm{Zn}$ diet $(10 \mathrm{mg} \mathrm{Zn} / \mathrm{kg}$ diet) for the following 5 . These groups were designated as control and marginal $\mathrm{Zn}$ respectively. All food was provided ad lib. and food intakes and body-weights monitored regularly. A non-pregnant control group of female Wistar rats $(250 \mathrm{~g})$ was also included in the study to distinguish the effects of pregnancy on carbohydrate metabolism per se.

On day 19 of pregnancy, the food pots were removed at 18.00 hours and the next morning (day 20 of pregnancy), animals from the two pregnant groups and the nonpregnant group were selected in random order and the following procedures carried out between 0.900 and 13.00 hours. Half the rats from each group were anaesthetized with sodium pentabarbitone $(200 \mathrm{mg} / \mathrm{kg}$ body-weight, intraperitoneally), blood taken by cardiac puncture, and the pancreas and fetuses removed for analysis. The other rats were given $1 \mathrm{mg}$ glucose/g body-weight (from a $2.78 \mathrm{M}$-glucose solution) by gavage. Tail-blood $(100 \mu \mathrm{l})$ was taken into heparinized tubes just before the glucose dose and 30 and $60 \mathrm{~min}$ later, and analysed for glucose. The rats were then subjected to the same procedures as the fasted animals.

Following all collections, blood samples were centrifuged and the plasma stored at $-20^{\circ}$ until analysis.

The fetuses from each litter were combined, freeze-dried and ground to a homogenous powder. The pancreases were oven-dried in silica crucibles for $18 \mathrm{~h}$ at $85^{\circ}$, ashed for $48 \mathrm{~h}$ and the ash taken up in hot hydrochloric acid (11.7 M) for $\mathrm{Zn}$ analysis by atomic absorption spectroscopy (PU 9000, Pye Unicam, Cambridge).

Protein was determined by the Biuret method (Layne, 1957) in approximately 60-mg samples of freeze-dried fetal tissue, using bovine serum albumin as the standard.

Samples of approximately $200 \mathrm{mg}$ of fetal tissue were analysed for DNA by a microfluorimetric technique using 3,5-diaminobenzoic acid (Fiszer-Szafarz et al. 1981).

Blood glucose was measured in duplicate $25-\mu \mathrm{l}$ samples of fresh heparinzed whole blood by the glucose oxidase ( $E C$ 1.1.3.4) method, using a glucose analyser (YSI Model 27; Yellow Springs Instruments Inc., Ohio).

Plasma insulin was determined by a radioimmunoassay using guinea-pig anti-insulin serum (Serono Diagnostics Ltd., Woking, Surrey) and ${ }^{125}$ I-iodinated insulin (Amersham International plc, Amersham, Bucks), as described by Scott et al. (1981). This method involves the adsorption of free hormone on to dextran-coated charcoal, and since nonspecific adsorption of this kind may be influenced by the protein content of plasma, a range of volumes was assayed for each plasma sample. Volumes of between 100 and $200 \mu 1$ were found to be most suitable. Insulin concentrations were calculated using rat insulin (Nova Labs Ltd, Basingstoke, Hants) as a standard.

\section{Expt 2}

Adult virgin female Wistar rats (250 g) were maintained and mated as described for Expt 1 , except that the marginal-Zn diet was given from days 15 to 19 of pregnancy. The groups were again designated as control and marginal-Zn. Food was provided ad lib. until day 19 when rats were given access to unrestricted amounts of food as meals between 10.00 and $11.00,14.00$ and 15.00 and 19.00 and 20.00 hours. Between 09.00 and 13.00 hours on day 20 of pregnancy, animals from each group were subjected, simultaneousiy, to the following procedures. Each rat was given $2.5 \mathrm{mg}$ glucose/g body-weight (from a $2.78 \mathrm{M}$ solution) by gavage. Tail blood $(100 \mu l)$ was taken into heparinized tubes just before the glucose dose and afterwards at timed intervals up to $60 \mathrm{~min}$, and glucose concentration determined. To minimize the stress caused by repeated sampling, blood was taken from half the animals in 
Table 1. Mean no. of fetuses per litter, wet fetal weight, water content and protein:DNA in fetuses from rats fed on the control or marginal-Zn diet during late pregnancy

(Values are means with their standard errors)

\begin{tabular}{|c|c|c|c|c|}
\hline \multirow[t]{2}{*}{ Dietary treatment $\uparrow \ldots$} & \multicolumn{2}{|c|}{ Control (n 22) } & \multicolumn{2}{|c|}{ Marginal-Zn $(n 17)$} \\
\hline & Mean & $\mathrm{SE}$ & Mean & SE \\
\hline No. fetuses & $12 \cdot 8$ & 0.7 & $12 \cdot 8$ & $1 \cdot 0$ \\
\hline Mean fetal wt (g) & $3 \cdot 39$ & 0.08 & $3 \cdot 64$ & $0 \cdot 11$ \\
\hline Water $(\mathrm{g} / \mathrm{kg})$ & 873 & 0.7 & 873 & 1.0 \\
\hline Protein:DNA (mg/mg) & $19 \cdot 1$ & 0.5 & $21 \cdot 4^{*}$ & 0.6 \\
\hline
\end{tabular}

* Mean value was significantly different from control value $(P<0.01)$.

$\dagger$ For details of dietary treatment, see p. 316.

each group at 10,30 and $50 \mathrm{~min}$ after dosing, and from the other half at 20,40 and $60 \mathrm{~min}$ after dosing. At 70 min post-dosing blood was taken by cardiac puncture under diethyl ether anaesthesia for glucose and insulin assay. Fetuses were removed and a pooled blood sample taken from each litter by decapitation for determination of both glucose and insulin concentration, although it was not always possible to collect enough blood for both assays. The number of observations made for each type of analysis is clearly stated in the tables of results. All analyses were performed as described in Expt 1.

A number of animals were eliminated from each experiment when they were found not to be pregnant. In Expt 1 there were twenty-two pregnant rats in the control group and seventeen in the marginal-Zn group. In Expt 2 there were nineteen pregnant rats in each group.

\section{Statistical analysis}

Results for the groups were subjected to one-way analysis of variance, and where this showed a treatment effect, groups were compared by Student's $t$ test. Comparisons of blood glucose concentrations at each time point after oral dosing were made using Student's unpaired $t$ test.

\section{RESULTS \\ Expt 1}

There was no difference in the mean body-weights of the pregnant rats at the end of the experiment, values being 365 (SE 18) and 357 (SE 26) $\mathrm{g}$ for the control and marginal-Zn groups respectively. Mean litter size and fetal water content were also similar in these two groups, but there was a significantly higher protein: DNA value $(P<0.01)$ in the fetuses from rats given the marginal- $\mathrm{Zn}$ diet between days 13 and 19 of pregnancy, compared with those given a diet adequate in $\mathrm{Zn}$. The difference between mean fetal weights was only significant $(P<0.05)$ when comparisons were made using a one-tailed $t$ test (Table 1), when the fetuses from rats given a marginal- $\mathrm{Zn}$ diet were shown to be heavier than fetuses from control animals.

Fasting blood glucose and insulin concentrations were similar in both pregnant groups, but the glucose levels were significantly lower and the insulin levels higher compared with the non-pregnant animals, as shown in Table 2. Following oral dosing, the 30 min increase in blood glucose was found to be significantly greater $(P<0.01)$ in the marginal-Zn group of rats, compared with both the pregnant and non-pregnant control-fed rats. After 60 min the values for the two groups of pregnant animals were similar but lower than those seen in the non-pregnant animals. 


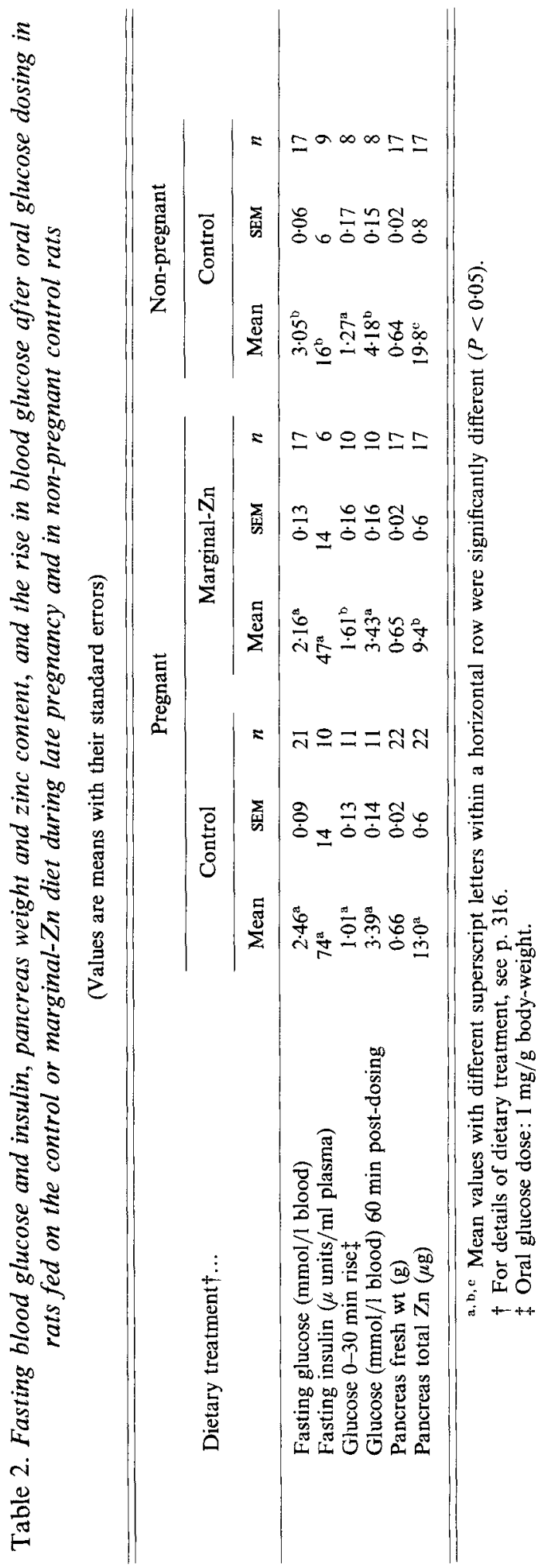




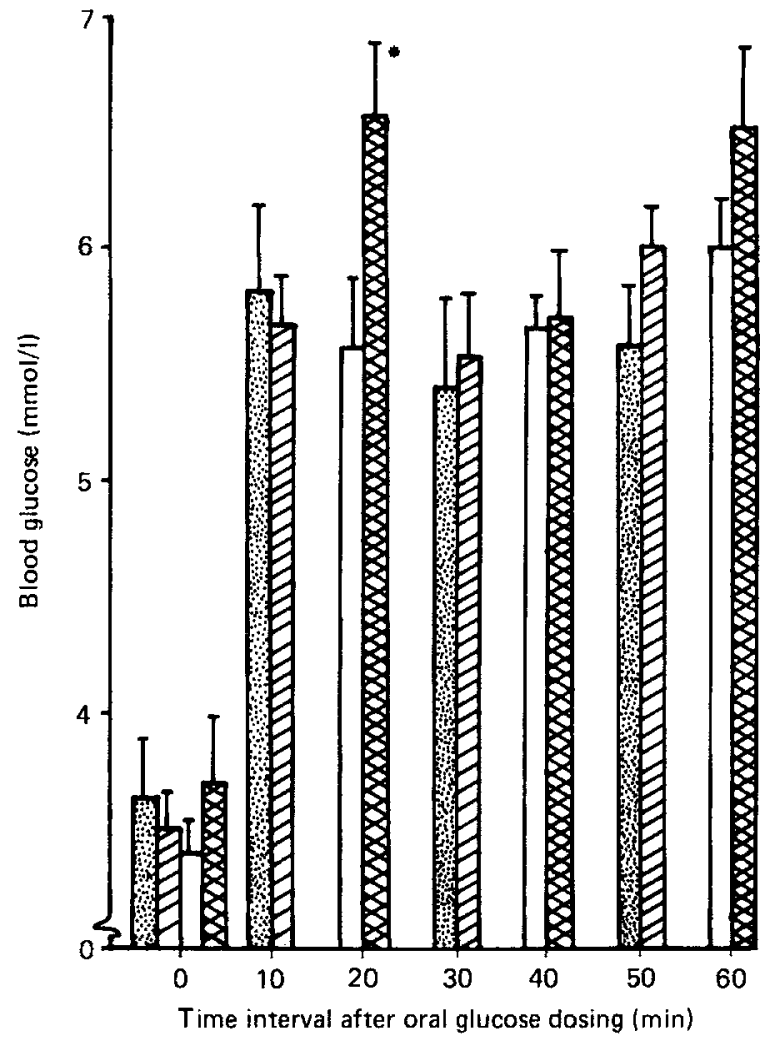

Fig. 1. Blood glucose concentrations, following an oral glucose dose $(2.5 \mathrm{mg}$ glucose $/ \mathrm{g}$ body-weight), in rats given the control diet throughout pregnancy $($ 圆, $\square$ ) or the control diet for $15 \mathrm{~d}$ followed by a marginal-zinc diet for $4 \mathrm{~d}$ (国, (for details of dietary treatment, see p. 361). Values are means, with their standard errors represented by vertical bars, for ten rats at the $0,10,30,50$ min sampling times (圈,

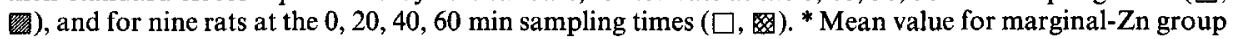
was significantly different from that for controls $(P<0.05)$.

Table 3. Maternal and fetal blood ${ }^{*}$ glucose and insulin concentration 70 min after oral dosing $\dagger$ in rats fed on the control or marginal-Zn diet during late pregnancy

(Values are means with their standard errors)

\begin{tabular}{|c|c|c|c|c|c|c|}
\hline \multirow[t]{2}{*}{ Dietary treatment $\ddagger \ldots$} & \multicolumn{3}{|c|}{ Control } & \multicolumn{3}{|c|}{ Marginal-Zn } \\
\hline & Mean & $\mathrm{SE}$ & $n$ & Mean & $\mathbf{S E}$ & $n$ \\
\hline \multicolumn{7}{|l|}{ Maternal } \\
\hline Glucose (mmol/1 blood) & $6 \cdot 0$ & 0.2 & 19 & $6 \cdot 1$ & $0 \cdot 3$ & 19 \\
\hline Insulin ( $\mu$ units $/ \mathrm{ml}$ plasma) & 90 & 9 & 19 & 97 & 11 & 19 \\
\hline \multicolumn{7}{|l|}{ Fetal } \\
\hline Glucose (mmol/1 blood) & $2 \cdot 4$ & 0.1 & 19 & 2.5 & 0.2 & 19 \\
\hline Insulin ( $\mu$ units/ml plasma) & 134 & 15 & 12 & 123 & 11 & 17 \\
\hline
\end{tabular}

* Maternal blood obtained by cardiac puncture; fetal blood by decapitation.

$\dagger$ Oral dose : $2 \cdot 5 \mathrm{mg}$ glucose/g body-weight.

$\ddagger$ For details of dietary treatment, see p. 316 . 
Total pancreatic $\mathrm{Zn}$ content of animals in the marginal-Zn group was substantially lower $(P<0.001)$ than that found in the control rats. Both groups of pregnant animals had significantly $(P<0.05)$ lower pancreatic $\mathrm{Zn}$ levels than non-pregnant rats fed on the control diet (Table 2).

\section{Expt 2}

As in the first experiment there was no difference in the final body-weights of rats in the two groups, values being similar to those in Expt. 1. Mean numbers of fetuses per litter were also similar (13.3 (SE 1.0) control group, 12.5 (SE 1.0) marginal-Zn group).

Results from the oral glucose tolerance test indicated that there was a small but significant change in the glucose tolerance of pregnant rats given a marginal- $\mathrm{Zn}$ diet in the last $4 \mathrm{~d}$ of pregnancy (Fig. 1). Measurements of blood glucose concentration at 20, 40 and $50 \mathrm{~min}$ post-dosing showed that, as in the first experiment, there was an increase in the initial rise in blood glucose, the effect being significant at approximately $20 \mathrm{~min}$, after which time levels were not significantly different from those of the controls.

Maternal and fetal blood glucose and plasma insulin concentrations measured $70 \mathrm{~min}$ post-dosing were similar in the two groups (Table 3).

\section{DISCUSSION}

Rats fed on a marginal-Zn diet between days of 13 and 19 of pregnancy showed a similar trend toward the production of heavier pups to that observed in a previous study (Fairweather-Tait et al. 1985), but in the present study the difference was only significant at the $5 \%$ level using a one-tailed $t$ test. However, there is some indication of a difference in fetal development between the two dietary groups since the protein:DNA value in fetuses from animals in the marginal- $\mathrm{Zn}$ group was significantly higher than that in fetuses from control-fed animals. The effect on fetal growth of marginal- $\mathrm{Zn}$ intake in late pregnancy was demonstrated more clearly in fetuses taken on the 21 st day of gestation (Fairweather-Tait et al. 1984) than on the 20th day, as in the present study, possibly because of the exponential nature of the growth which is maximal between days 20 and 21 in the rat (Southgate, 1971). This trend toward increased fetal weight contrasts with the effects of severe $\mathrm{Zn}$ deficiency on fetal growth (Hurley \& Mutch, 1973), as discussed elsewhere (Fairweather-Tait et al. 1985), where it was suggested that the increment in fetal growth, observed in rats given marginal- $\mathrm{Zn}$ diets towards term, might be associated with changes in carbohydrate metabolism, hypertrophy being a characteristic feature of offspring of diabetic mothers (Ogata et al. 1980). The studies described in the present paper contain preliminary findings which supports this hypothesis.

The pregnant state is associated with marked changes in maternal fuel-hormone metabolism. Comparison of the pregnant and non-pregnant animals, in the first experiment, clearly demonstrated the fasting hypoglycaemia and hyperinsulinaemia which are characteristic of pregnancy (Adam \& Felig, 1978). It was also noted in the present study that pregnancy resulted in a substantial decrease in pancreatic $\mathrm{Zn}$ content. This may be associated with the hyperinsulinaemia observed in these animals, since increased insulin secretion has been shown to result in a decrease in islet tissue Zn (Kirchgessner \& Roth, 1983). The further decrease in pancreatic $\mathrm{Zn}$ concentration observed in the marginal- $\mathrm{Zn}$ group of pregnant rats is consistent with many other studies showing that this tissue is one of the most sensitive tissues of $\mathrm{Zn}$ metabolism and responds rapidly to a reduction in dietary $\mathrm{Zn}$ intake (Williams \& Mills, 1970). The importance of $\mathrm{Zn}$ for insulin storage and function has long been recognized (Scott, 1934), but the relation between sub-optimal $\mathrm{Zn}$ intake and insulin metabolism in vivo remains obscure. Dietary $\mathrm{Zn}$ depletion has been reported to result in diminished insulin storage and secretion, increased rate of insulin 
degradation and the development of insulin resistance (Kirchgessner \& Roth, 1983). However, findings on the effects of dietary $\mathrm{Zn}$ depletion on insulin metabolism are often contradictory, primarily because of the alterations in voluntary food intake and patterns of feeding which often accompany experimental $\mathrm{Zn}$ deficiency. Clearly, the pregnant animals in the present study were able to maintain a high fasting circulating insulin level despite substantial decreases in pancreatic $\mathrm{Zn}$ content. Nevertheless, the possibility that the further reduction in pancreatic $\mathrm{Zn}$ observed in the marginal- $\mathrm{Zn}$ rats may be associated with diminished insulin stores, or reduced physiological potency of the hormone, should be considered in future work.

A possible difference in insulin metabolism between the control and marginal- $\mathrm{Zn}$ pregnant animals was indicated by the difference in the rate of blood glucose clearance. In the first experiment pregnant rats given the marginal- $\mathrm{Zn}$ diet in late pregnancy had a significantly greater $0-30 \mathrm{~min}$ rise in blood glucose concentration, following an oral glucose dose, than both non-pregnant and pregnant controls. To investigate this effect further, a second study was performed in which the oral glucose dose was increased, blood samples were taken more frequently, and food intake, time of feeding and period of fasting before the glucose tolerance test were strictly controlled. In addition, the period during which rats were given the marginal- $\mathrm{Zn}$ diet was limited to $4 \mathrm{~d}$ (days 15-19 of pregnancy), since previous work indicated that the response to transient marginal-Zn intake during pregnancy was greater over this shorter time period (Fairweather-Tait et al. 1985). The results from the second study confirmed our earlier finding that there was evidence of a significant increase in the early rise in blood glucose concentration after oral glucose dosing in rats given a marginal- $\mathrm{Zn}$ diet during the latter part of pregnancy. However, the 30-70 min postdosing values for blood glucose concentration were similar in both groups. Abnormal glucose tolerance, particularly following intraperitoneal administration of glucose, has been demonstrated on several occasions in $\mathrm{Zn}$-deficient laboratory rodents and human subjects (Quarterman et al. 1966; Sandstead et al. 1967). However, these alterations in glucose tolerance, together with evidence of abnormal insulin metabolism and increased rates of glucose absorption, were all associated with a prolonged period of severe mineral depletion (Kirchgessner \& Roth, 1983; Southon et al. 1984). In view of the relatively minor degree of dietary $\mathrm{Zn}$ deprivation imposed on the marginal-Zn animals in the present study, the changes in glucose utilization, and fetal growth and composition, reported in this and in a previous investigation, are difficult to explain. It is possible that the alterations in carbohydrate metabolism known to occur during pregnancy (Adam \& Felig, 1978), together with the additional demand for $\mathrm{Zn}$ by the developing fetus, increase the sensitivity of the mother to variations in dietary $\mathrm{Zn}$ intake, particularly during the period of very rapid fetal growth.

In the second experiment it was found that insulin and glucose concentrations in pooled fetal blood samples taken 70 min after the maternal glucose dose were similar in the two groups, but the possibility of differences occurring before this time has not yet been tested. It is thought that fluctuations in maternal blood glucose provide a stimulus for fetal insulin release, excessive insulin being a primary factor in fetal overgrowth (Hill, 1976). It is possible, therefore, that a small but consistent hyperglycaemic response following the ingestion of a meal, such as observed in the pregnant marginal- $\mathrm{Zn}$ rats, might result in an increment in fetal insulin release, thus promoting growth. This would provide an explanation for the significant increase in fetal weight observed in our previous study, and the change in protein:DNA value demonstrated in the present investigation.

The change in glucose tolerance in the pregnant rats given the marginal- $\mathrm{Zn}$ diet towards term was relatively small but the dietary manipulation was of a very minor nature. Alterations in carbohydrate metabolism occur normally in pregnancy, and glucose 
tolerance is often impaired towards the end of pregnancy. Even the minor changes in glucose utilization demonstrated in the present study may therefore be important during pregnancy. The implication of these findings with respect to human pregnancy, particularly where there is evidence of gestational diabetes, warrants further investigation.

\section{REFERENCES}

Adam, P. A. J. \& Felig, P. (1978). In Human Growth, 1 Principles and Prenatal Growth, pp. $461-548$ [F. Falkner and J. M. Tanner, editors]. New York and London: Plenum Press.

Baer, M. T., King, J. C., Tamura, T., Margen, S., Bradfield, R. B., Weston, W. L. \& Daugherty, N. A. (1985). American Journal of Clinical Nutrition 41, 1220-1235.

Fairweather-Tait, S. J., Wright, A. J. A., Cooke, J. \& Franklin, J. (1985). British Journal of Nutrition, 54, $401-413$

Fairweather-Tait, S. J., Wright, A. J. A. \& Williams, C. M. (1984). British Journal of Nutrition 52, $205-213$.

Fiszer-Szarfarz, B., Szarferz, D. \& Alba de Murilla, A. (1981). Analytical Biochemistry 110, 165-170.

Hill, D. E. (1976). Progress in Clinical and Biological Research 10, 127-139.

Hurley, L. S. \& Mutch, P. B. (1973). Journal of Nutrition 103, 649-656.

Kirchgessner, M. \& Roth, H. P. (1983). In Metal Ions in Biological Systems, pp. 363-414 [A. Sigel, editor]. New York: Marcel Dekker.

Layne, E. (1957). In Methods in Enzymology, vol. 3, pp. 450-451 [S. P. Colowick and N. O. Kaplan, editors]. New York: Academic Press.

Ogata, E. S., Sabbagha, R., Metzger, B. E., Phelps, R. L., Depp, R. \& Freinkel, N. (1980). Journal of the American Medical Association 243, 2405-2408.

Quarterman, J., Mills, C. F. \& Humphries, W. R. (1986). Biochemical and Biophysical Research Communications 25, 354-358.

Reeves, P. G. \& O'Dell, B. L. (1983). British Journal of Nutrition 49, 441-452.

Sandstead, H. H., Prasad, A. S., Schulert, A. R., Farid, Z., Miale, A., Bassilly, S. \& Darby, W. J. (1967). American Joumal of Clinical Nutrition 20, $422-442$.

Schwartz, R. (1968). Proceedings of the Royal Society of Medicine 61, 1231-1236.

Scott, A. M., Atwater, I. \& Rojass, E. (1981). Diabetologia 21, 470-475.

Scott, D. A. (1934). Biochemical Journal 28, 1592-1602.

Southgate, D. A. T. (1971). Biology of the Neonate 19, 272-292.

Southon, S., Gee, J. M. \& Johnson, I. T. (1984). British Journal of Nutrition 52, 371-380.

Williams, R. B. \& Mills, C. F. (1970). British Journal of Nutrition 24, 989-1003. 